\title{
Caretakers' understanding of malaria, use of insecticide treated net and care seeking-behavior for febrile illness of their children in Ethiopia
}

Zewdie Birhanu ${ }^{1 *}$, Yemane Ye-ebiyo Yihdego ${ }^{2}$ and Delenasaw Yewhalaw ${ }^{3,4}$

\begin{abstract}
Background: Local understandings of malaria and use of preventive measures-are critical factors in sustained control of malaria. This study assessed caretakers' knowledge on malaria, use of Long Lasting Insecticide Treated Nets (LLINs) and care-seeking behavior for their children's illness in different malaria transmission settings of Ethiopia.

Methods: Data were collected from 709 caretakers of children of 2-9 years of age during in 2016. A standard questionnaire was used to assess caretakers' perceptions of malaria, use of LLIN and care seeking behavior for febrile illness of children aged 2-9 years.

Results: The caretakers recognized malaria mostly by chills $(70.4 \%, 499 / 709)$, fever $(45.7 \%, 324 / 709)$ and headache (39.8\%, 282/709). Overall, only 66.4\% (471) of the caretakers knew that mosquito bite caused malaria and that it was quite heterogeneous by localities (ranging from $26.1 \%$ to $89.4 \%$ ) and altitude $(p<0.05$ ). Majority, $72.2 \%$ (512), of the caretakers knew that sleeping under LLIN could prevent malaria. Overall knowledge on malaria (mean $=51.2 \%$ ) was very low with significant variations by localities, altitude and levels of malaria transmission, being low in high altitude and low in transmission areas $(p<0.05)$. Four hundred ninety-one $(69.3 \%, 491 / 709)$ of the children slept under LLIN in the previous night. Of malaria related knowledge items, only knowledge of LLIN was associated with net use; non-use of LLN was higher among caretakers who did not know the role of LLIN (AOR $=0.47,95 \% \mathrm{Cl}: 0.28-0.77, p=0.003$ ). Of course, attributing causation of malaria to stagnant water discouraged use of net $(p=0.021)$. Of febrile children $(n=122)$, only 50 (41.0\%) sought care with only 17 (34.0\%) seeking the care promptly. There was no significant link between knowledge of malaria and care seeking behavior $(p>0.05$ ). However, knowledge of malaria had some level of influence on treatment source preference where caretakers with greater knowledge preferred pharmacy as source of care.

Conclusions: The findings demonstrated that caretakers' understanding of malaria was unsatisfactory with marked heterogeneity by localities. The present evidence suggests that knowledge is not sufficient enough to drive LLIN use and care seeking. Yet, context-specific health education interventions are important besides ensuring access to necessary preventive tools.
\end{abstract}

Keywords: Malaria, Caretakers, Malaria Perception, Malaria Knowledge, LLIN, Care Seeking, Fever, Ethiopia

\footnotetext{
* Correspondence: zbkoricha@yahoo.com

'Department of Health, Behavior and Society, Faculty of Public Health, Jimma

University, Jimma, Ethiopia

Full list of author information is available at the end of the article
} International License (http://creativecommons.org/licenses/by/4.0/), which permits unrestricted use, distribution, and reproduction in any medium, provided you give appropriate credit to the original author(s) and the source, provide a link to the Creative Commons license, and indicate if changes were made. The Creative Commons Public Domain Dedication waiver (http://creativecommons.org/publicdomain/zero/1.0/) applies to the data made available in this article, unless otherwise stated. 


\section{Background}

Malaria is one of the oldest mosquito-borne diseases [1]. It is characterized by several clinical manifestations such as sensation of cold, fever, chills, headaches, nausea and vomiting, sweating, joint pain, prostration, and general malaise [2-4]. Despite remarkable progress to-date, malaria remains one of the major public health challenges around the world $[1,5,6]$. In 2015, an estimated 214 million cases of malaria were recorded globally. The African region contributed to about $88 \%$ of the world's malaria cases and $90 \%$ of the global death due to malaria $[1,6]$. Through effective community based health service delivery approaches such as Health Extension Program (HEP) and organized community networks called Health Development Army (HDA) volunteers combined with effective case management, Ethiopia has made a significant progress in reduction of malaria burden [7-13]. However, malaria continues to be an important public health problem in Ethiopia [14-16]. About 61 million (60\%) of the population of the country are at risk of malaria infection, and in 2014/2015, over two million (presumptive and laboratory confirmed) cases of malaria were reported $[14,16]$.

In accordance with the global malaria elimination program (2016-2030) [1, 17, 18], Ethiopia has also given a considerable attention to malaria elimination program with a vision to pave the way for a malariafree nation by $2030[12,19]$. Improving local community understandings of malaria and use of preventive strategies are among the key priority intervention areas for sustained control and the move towards elimination targets $[1,12]$. This is because malaria elimination initiatives require higher level of active community engagement to sustain core malaria prevention behaviors despite reduction in disease prevalence [20]. As the prevalence of the disease drops, maintaining communities' awareness and appropriate behaviors are more challenging as the diseases is no longer perceived as a risk and local perceptions continued to hinder accurate impressions of this disease and use of preventive measures [20]. Ethiopia has planned to raise community awareness on causation and preventive measures of malaria to $100 \%$ by 2020 [12, 19]. In Ethiopia, Long Lasting Insecticidal Treated Net (LLIN) is one of the key national malaria control strategies [7, 12, 21], and the national target sets a $100 \%$ coverage of all households in malarious areas with at least two LLINs per household [12] and reach 86\% LLIN use among vulnerable groups by 2020 [12]. Similarly, early recognition and prompt care seeking is vital for effective diagnosis and management of malaria [22-24]. It is recommended that every suspected malaria case needs to be confirmed either by microscopy or Rapid Diagnostic Test (RDT) before treatment is initiated [1, 5, 22-24].
To this end, access to malaria diagnosis has been decentralized to community level health facilities through the introduction of RDTs in Ethiopia since 2004 [7, 12, 21, 25].

In the context of elimination targets, it is essential to continuously monitor local understandings and perceptions that influence utilization of malaria preventive measures for evidence-based programing [1, 20]. However, little is documented regarding caretakers' perceptions on malaria and use of preventive measures by their children, mainly use of LLIN and care seeking behavior in different malaria transmission settings of Ethiopia. Thus, this study aimed at assessing caretakers' knowledge on malaria and use of LLIN and care seeking behaviors for childhood febrile illness. In addition, it examined the relationship between malaria related knowledge and children's use of LLIN and care seeking practice in response to febrile illness. The findings could help to devise appropriate and context-specific interventions to support ongoing malaria prevention control and elimination efforts in Ethiopia and other similar settings.

\section{Methods}

\section{Study setting}

The study was conducted mainly in sentinel sites established for malaria surveillance in Ethiopia [26, 27]. The sentinel sites were chosen to generate evidence that supports the ongoing malaria surveillance and epidemic detection efforts in the country. The surveillance sites consisted of ten Primary Health Care Units (PHCUs) covering a large geographic area- low to high transmission contexts, and diverse eco-epidemiologic settings in Ethiopia [27, 28]. Each PHCU consists of one health center and five satellite community level health posts. The health centers provide diagnosis using microscopy and treat uncomplicated malaria cases [7, 29]. At health post level, HEWs conduct diagnosis of malaria using multi-species RDT and provide appropriate treatment accordingly [7, 25, 29]. Eight of the ten sentinel sites were included in the study and two sites (Shebe Sombo and Goda Dhera) were added from non-sentinel sites. The selected sentinel sites were characterized by the occurrence of multiple malaria species, diverse transmission pattern and altitude [27].

\section{Population and sample size}

The data were collected in June 2016 as part of a larger community based cross sectional study conducted to quantify malaria endemicity levels in Ethiopia. The larger study was proposed to involve 1040 children aged 2-9 years and finally, 763 children were enrolled in the study. As part of the study, the caretakers of each child were enrolled in the study $(n=763)$ to assess their perceptions of malaria. Hence, this analysis focused on 
caretakers' perceptions of malaria and its preventive measures, and examined its association with use of LLIN and care seeking among children 2-9 years of age. In this case, caretakers were mostly parents (either mothers or fathers), and in few cases, sisters, brothers or other close relatives were presented as caretakers.

\section{Sampling technique}

Study participants (i.e. caretakers accompanying their children) were sampled from ten PHCUs. The detailed sampling process was implemented as follows. The sample size (1040 children with their caretakers) was equally allocated to each PHCU. Additionally, two satellite health posts, which were part of the respective PHCU, were randomly selected. Equal number of children along with the respective caretakers was considered from each of the selected health post. Within the selected health posts, the list of households with eligible children (aged 2-9 years) was obtained from family the register. Simple random sampling was used to select eligible households using the list obtained from health post level. Then, caretakers were invited to participate in the study through local administrators, community volunteers and community based health workers, mainly health extension workers. Caretakers were invited to come to the nearest health facility (e.g. health center or health post). Upon arrival, caretakers were given detailed information about the study and signed written consent form in expression of agreement to participate to the study.

\section{Measurements}

A standard questionnaire, adapted from literatures, was used to assess caretakers' knowledge on malaria and their children's use of LLIN and care-seeking behaviors $[9,30]$. Nine questions which addressed signs and symptoms of malaria, perception of causation, preventive measures and vulnerable groups were used to measure caretakers' knowledge on malaria. Overall knowledge was computed from the most important knowledge items: knowledge of three basic symptoms of malaria (fever/hot body, chills/shivering, and headache); causation of malaria (i.e. mosquito bite); knowledge of the three classical malaria preventive measures (insecticide treated net, Indoor Residual Spraying (IRS) and environmental management), and knowledge of vulnerable groups to malaria infections (i.e. children under the age of five and pregnant women). Correct response was coded as " 1 " and incorrect response was coded as " 0 ". Then, the scores were summed up to produce a composite score and finally, the result was adjusted to $100 \%$. This knowledge score was used for further analysis. Caretakers' and their children's background information such as age, sex were also recorded.
Caretakers provided information about experience of fever within two weeks recall period immediately preceding the survey. Prompt care-seeking behavior was defined as seeking care from health facilities within $24 \mathrm{~h}$ of onset of fever. In addition, caretakers were asked about LLIN ownership (i.e. proportion of households in the study with at least one LLIN) and LLIN use the previous night preceding the survey. Households who owned at least one LLIN for every two people of the household members were defined as having sufficient access to LLIN within the households.

\section{Malaria transmission levels}

Serological Markers (SM) of exposure to infections was used to define malaria transmission levels by localities. The test was based on the binding of specific antibodies present in the human plasma to antigens immobilized on a 96-well Enzyme Immuno Assay (EIA) plate. The test detects antibodies (i.e. IgG, IgM and IgA) to the four species of Plasmodium parasite; P.falciparum, $P$. vivax, $P$. ovale and $P$. malariaeduring all stages of infections process, and was performed as recommended by the manufacturer [31]. Detailed assay procures is available in earlier article [26]. Based on serological marker, malaria transmission level was defined as low $(\mathrm{SM}<10 \%)$, moderate (SM: $11-50 \%)$ and high $(\mathrm{SM}>$ $51 \%)$. Similarly, for the purpose of comparisons of key findings, altitude above sea level was classified as low (elevations $<1500 \mathrm{~m})$, mid (1500-2000 m) and high (>2000 m).

\section{Data collection methods}

The data were collected through questionnaire interviewers administered by trained and experienced interviewers. The questionnaire was translated into the local language (Afan Oromo) and back translated into English to check for consistency and appropriateness. The Afan Oromo version was pre-tested in a similar setting. Data collection process was closely supervised by the investigators. Caretakers were interviewed at the nearest health facility (health center/health post).

\section{Data processing and analysis}

The data were analyzed using SPSS software package version 21.0. Descriptive statistics such as mean and frequency distribution were used to present the findings. Key findings were sorted by altitude, malaria transmission levels and study sites. Chi-square test was used to assess the association between knowledge of malaria with some selected factors such as study sites, altitude and malaria transmission levels. In addition, Spearman ( $r$ ) test was used to examine the relationship between knowledge of causality and prevention strategies. One-way ANOVA was used to compare mean 
knowledge score by selected background factors. Logistic regression was used to assess the association between malaria related knowledge and use of LLIN/ care-seeking behavior for fever. A 95\% confidence interval and $p$-value less than 0.05 were used to declare statistically significant association.

\section{Results}

\section{Background characteristics of caretakers}

Overall, 778 caretakers were invited for participation, and finally, 709 (91.3\%) caretakers were enrolled in the study. Table 1 presents background characteristics of caretakers. Nearly two-third of the caretakers had no formal education and caretakers belonged to Oromo ethnic group accounted for 601 (84.8\%).

\section{Recognition of malaria}

In this study, 702 (99.0\%) of the caretakers reported that they knew malaria. Table 2 shows the signs and symptoms of malaria mentioned by the participants. Consequently, chills, and fever/hot body were the most frequently reported symptoms of malaria which accounted for 499 (70.4\%), 324 (45.7\%), respectively. Headache was mentioned by $282(39.8 \%)$ of the caretakers. The proportion of caretakers who knew the three classical symptoms of malaria (i.e. chills, fever and headache) was very low (14.4\%), with little variations by altitude. Accordingly, 17.1\% [32], 13.3\% [33] and 9.5\% [7] of the caretakers knew the three classical signs and symptoms in low, mid and high altitude areas, respectively. Twenty six (3.7\%) of the caretakers said that they do not know any signs or symptoms of malaria.

Table 1 Background characteristics of caretakers, Ethiopia

\begin{tabular}{|c|c|c|c|}
\hline Background characteristics & Category & Frequency & $\%$ \\
\hline \multirow[t]{5}{*}{ Age } & $18-24$ & 137 & 19.3 \\
\hline & $25-34$ & 344 & 48.5 \\
\hline & $35-44$ & 159 & 22.4 \\
\hline & $45-54$ & 44 & 6.2 \\
\hline & $\geq 55$ & 25 & 3.5 \\
\hline \multirow[t]{2}{*}{ Sex } & Male & 102 & 14.4 \\
\hline & Female & 607 & 85.6 \\
\hline \multirow[t]{3}{*}{ Residence } & Rural & 563 & 72.4 \\
\hline & Urban & 111 & 14.3 \\
\hline & Semi-urban & 104 & 13.4 \\
\hline \multirow[t]{3}{*}{ Level of education } & No formal education & 468 & 66.0 \\
\hline & Primary school (1-8) & 199 & 28.1 \\
\hline & Secondary school and above (9-12) & 42 & 5.9 \\
\hline \multirow[t]{4}{*}{ Religion of caretaker } & Muslim & 454 & 64.0 \\
\hline & Orthodox & 187 & 26.4 \\
\hline & Protestant & 62 & 8.7 \\
\hline & Others $^{a}$ & 6 & 0.8 \\
\hline \multirow[t]{4}{*}{ Ethnicity } & Oromo & 601 & 84.8 \\
\hline & Amhara & 49 & 6.9 \\
\hline & Gurage & 20 & 2.8 \\
\hline & Others $^{b}$ & 39 & 5.5 \\
\hline \multirow[t]{7}{*}{ Caretakers' occupation } & Farmer & 494 & 69.7 \\
\hline & Private business job & 53 & 7.5 \\
\hline & Housewife & 43 & 6.1 \\
\hline & Jobless & 37 & 5.2 \\
\hline & Merchant & 28 & 3.9 \\
\hline & Daily laborer & 22 & 3.1 \\
\hline & Others $^{c}$ & 32 & 4.5 \\
\hline
\end{tabular}

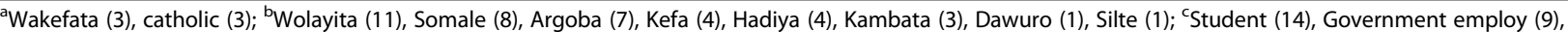
Local alcohol makers (5), Small business (2), Commercial sex worker (1), Driver (1) 
Table 2 Caretakers' knowledge of signs and symptoms of malaria, Ethiopia

\begin{tabular}{lll}
\hline Sign and symptoms & Frequency & $\%$ \\
\hline Chills/shivering & 499 & 70.4 \\
Fever/hot body & 324 & 45.7 \\
Headache & 282 & 39.8 \\
Nausea and vomit & 124 & 17.5 \\
Loss of appetite & 108 & 15.2 \\
Thirsty & 59 & 8.3 \\
Back pain & 50 & 7.1 \\
Weakness & 28 & 3.9 \\
Don't know & 26 & 3.7 \\
Diarrhea & 20 & 2.6 \\
Others $^{\mathrm{a}}$ & 48 & 6.6 \\
\hline
\end{tabular}

${ }^{a}$ Sour taste (16), Cough (10), Joint pain (8), Dizziness (6), swelling of face, leg, abdomen (3), Abdominal cramp (2), Swelling of spleen, (rajijii dhiiteessu-1), Hernia 'kuukkii garaa' (1), Sweating (1)

Perceptions on causations and preventive strategies of malaria Two-third (66.4\%) of the caretakers directly linked causation of malaria to mosquito bite with significant variations by altitude $(p=0.001,73.5 \%$ at low, $61.4 \%$ at mid and $64.9 \%$ at high altitude) and localities $(p=0.001)$. Likewise, knowledge of mosquito bite as route of malaria transmission was the highest in Metehara (89.4\%), Bulbula (85.9\%) and Goda Dhera (73.6\%). In contrast, knowledge of mosquito bite was extremely low in some study sites such as Dembi (26.1\%), Kersa (36.5\%) and Shebe Sombo (43.9\%). Knowledge of mosquito bite did not significantly vary by malaria transmission levels $(p>0.05)$. In fact, the proportion of caretakers who knew mosquito bite as route of malaria transmission was the highest in high malaria transmission areas $(70.8 \%, 46 / 65)$ and the lowest in low transmission areas $(63.3 \%, 273 / 431)$. In moderate transmission areas, $71.4 \%(152 / 213)$ of the caretakers were aware that mosquito bites cause malaria. Moreover, a considerable proportion of caretakers associated malaria with different conditions such as stagnant water $(9.4 \%)$, poor sanitation and hygiene (9.4\%), and cold weather (6.3\%). The analysis revealed that twenty different misperceptions on causations of malaria were recorded even though some of these misconceptions were less frequent or mentioned by few caretakers (Table 3).

\section{Knowledge of preventive measures of malaria}

This study identified that perceptions on prevention methods of malaria was very diverse with numerous misconceptions. In fact, about two-third (72.2\%) of the caretakers mentioned that sleeping under insecticide treated mosquito net prevents malaria. In addition, valid malaria preventive strategies such as cleaning home surroundings and draining stagnant water were reported by $275(38.8 \%)$ and $113(15.9 \%)$ of the caretakers, respectively. However, a significant proportion of caretakers also believed that practices such as using toilet, keeping personal hygiene, using clean water for drinking, use of onion, eating hot pepper, and not eating fruits such as mango, avocado, drinking bile etc. prevent malaria (Table 3 ).

Figure 1 shows knowledge of core malaria preventive measures by altitude. Knowledge of LLIN did not vary by altitude $(p>0.05)$ whereas knowledge of indoor residual spraying and environmental management significantly varied by altitude $(p<0.001)$. Consequently, the proportion of caretakers who knew that IRS prevents malaria was consistently low at all ranges of altitude. Of course, the difference was not significant; it was relatively better in areas of low altitude (13.5\%). In contrast, the proportion of caretakers who knew environmental management as core malaria preventive measure was significantly the highest in mid altitude areas and the lowest in low altitude areas. Moreover, knowledge of these core malaria preventive measures were quite heterogeneous and significantly varied $(p<0.001)$ by localities. For instance, knowledge of LLIN was as low as 26.1\% (in Dembi) and as high as $90.6 \% \%$ (in Metehara) (Fig. 2).

\section{Coherence between knowledge of malaria causality and prevention strategies}

This study indicated that caretakers' knowledge on causal factors and prevention rules of malaria was weak and incoherent. Knowledge of mosquito bite as a route of malaria transmission was moderately positively correlated with knowledge of LLIN $(r=0.473$, $p=0.001)$ and knowledge of IRS $(r=0.137, r=0.001)$. However, knowledge of mosquito bite was negatively correlated with knowledge of environmental management $(r=-0.113, p=0.003)$. Likewise, knowledge of LLIN and environmental management was negatively correlated with each other $(r=-0.183, \mathrm{p}=0.001)$. On the other hand, knowledge of IRS positively went with knowledge of LLIN $(r=0.109, p=0.004)$, but negatively went with knowledge of environmental management $(r=-0.013, p=0.006)$.

\section{Knowledge on vulnerable groups to malaria infections}

Over half, 408 (57.5\%), of the caretakers identified that children under the age of five were most vulnerable to acquire malaria infections. Nevertheless, only 158 $(22.3 \%)$ of the caretakers mentioned that pregnant women were one of the vulnerable groups to malaria infections. Overall, only $128(18.1 \%)$ of the caretakers mentioned that pregnant women and children under the age of five years were most at risk to malaria 
Table 3 Perception of causations and preventive strategies of malaria, Ethiopia

\begin{tabular}{|c|c|c|}
\hline & Frequency & $\%$ \\
\hline \multicolumn{3}{|l|}{ Perception of causation } \\
\hline Misquote bite & 471 & 66.4 \\
\hline Stagnant water & 67 & 9.4 \\
\hline Poor sanitation/hygiene & 67 & 9.4 \\
\hline Weather or cold & 45 & 6.3 \\
\hline Foul smell from dirty things & 43 & 6.1 \\
\hline Drinking dirty water & 36 & 5.1 \\
\hline Hunger & 19 & 2.7 \\
\hline Diets $^{a}$ & 16 & 2.3 \\
\hline Don't know & 38 & 5.4 \\
\hline Others $^{\mathrm{b}}$ & 54 & 7.6 \\
\hline \multicolumn{3}{|l|}{ Knowledge of prevention strategies } \\
\hline Sleeping under Insecticide treated net & 512 & 72.2 \\
\hline Clean home and surroundings & 275 & 38.8 \\
\hline Draining stagnant water & 113 & 15.9 \\
\hline Spraying home and around with Indoor Residual Spraying chemicals & 50 & 7.1 \\
\hline Sanitation and personal hygiene & 27 & 3.8 \\
\hline Using toilet & 18 & 2.5 \\
\hline Eating good diet & 17 & 2.4 \\
\hline Avoid walking in rain & 15 & 2.1 \\
\hline Drinking clean water & 13 & 1.8 \\
\hline Don't know & 54 & 7.6 \\
\hline Others $^{c}$ & 26 & 3.4 \\
\hline
\end{tabular}

adirty, cold, leftover, sweaty, roasted maize, sugarcane, fruits (mango, Papaya, avocado, tomato)

b walking in weed (13), flower from trees (13), Getting soaked with rain water (8), Walking in sun (6), Thirsty (3), dressing hot and moist clothes (1), walking in wet grass (1), earth's soul-'Afura lafaa' (1), Contamination by flies (1), Parasite/rammoo adda adda (1)

'Eating fresh food (5), eating chill or pepper (3), closing doors (3), smoking (2), avoid walking during sunny time (2), avoid cold weather (2), eating onion (2), avoid eating sugarcane (1), not eating sweaty food (1), avoid fruits such as papaya (1), drinking bile (hadhoftu-1), avoid eating roasted maize (1), spraying fleet (1), not eating damaged avocadao (1)

infections. On the other hand, 93 (13.1\%) of the caretakers stated that they did not know specific groups at risk of or vulnerable to malaria infection. The proportion of caretakers who knew that pregnant women $(39.2 \%, 29 / 74)$ and children under the age of five years $(75.7 \%, 56 / 74)$ are vulnerable to malaria infection was significantly $(p<0.005)$ higher in areas with high altitude. In low altitude areas, only $18.5 \%$ (51/ $275)$ and $56.0 \%(154 / 275)$ of the caretakers mentioned pregnant women and children under the age of five as vulnerable group to malaria, respectively. On the other hand, in mid altitude areas, $21.7 \%$ (78/360) and $55.0 \%(198 / 360)$ of the caretakers mentioned pregnant women and children under age five, respectively.



Fig. 1 Knowledge of core malaria preventive measures by altitude, Ethiopia 
$\square$ LLIN $\square$ Environmental management $\quad$ IRS

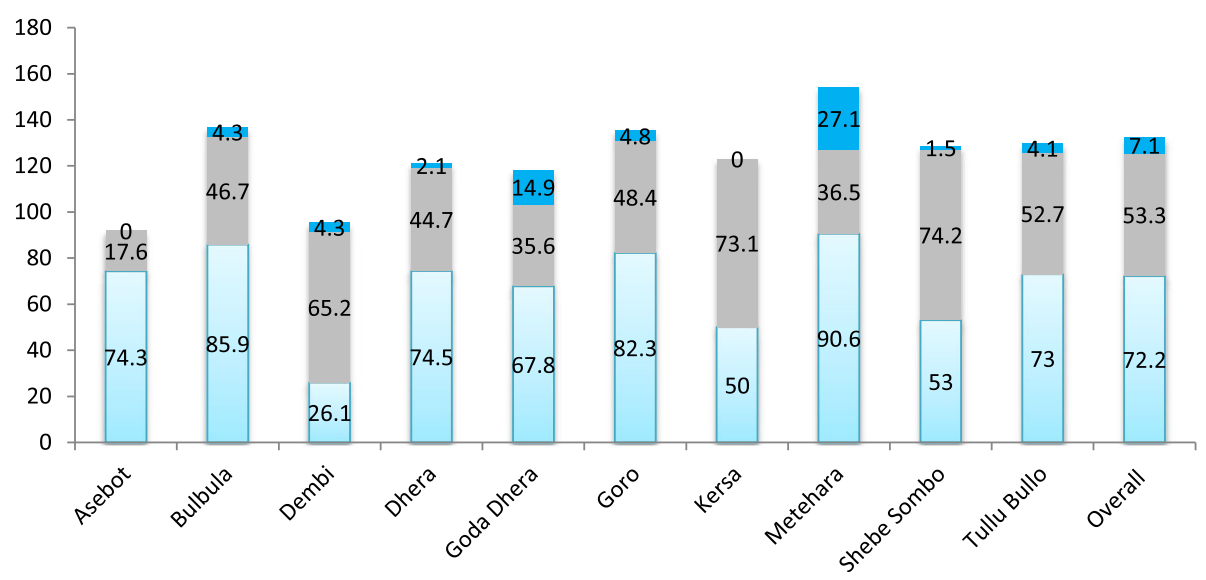

Fig. 2 Knowledge of core malaria preventive measures by localities, Ethiopia

Overall knowledge about malaria and its preventive measures Overall mean knowledge score was quite low (i.e. 51.2\%, 95\%CI: 49.6-52.8\%) with significant variations by localities $(P=0.001)$. With respect to localities, the highest mean score was recorded in Goro (mean $=62.2 \%$, 95\%CI: 56.2-68.1\%) followed by Goda Dhera (57.6\%, 95\%CI: 52.8-62.3\%). The lowest mean knowledge score was documented in Dembi (mean = $29.5 \%$ ) and Kersa (mean $=37.4 \%$ ). Mean knowledge score was significantly low in low malaria transmission areas (48.0, 95\% CI: 45.9-50.1). Caretakers who resided in areas of moderate $(55.9,9 \% \mathrm{CI}$ : 53.1-58.7) and high (57.2, 95\%CI: 49.6-52.8) malaria transmission scored higher mean knowledge $(p=0.001)$. Moreover, mean knowledge scores were 52.7 (50.2, $55.3), 49.2(47.0,51.2)$ and $55.9(50.3,61.4)$ in low, mid and high altitude areas, respectively $(p=0.019)$.

\section{Relationship between caretakers' malaria related knowledge and use of LLIN by children 2-9 years of age Ownership and access to LLIN}

Six hundred fifty eight (92.8\%, 95\%CI: 90.9-94.7) of the caretakers reported that they had at least one LLIN in their houses. However, only 299 (42.2\%) of the households had sufficient nets for every member of the household (i.e. 1 net for every 2 people). The rate of access to LLIN significantly varied by study sites (ranging from $13.0 \%$ to $65.2 \%)$. However, it did not significantly vary by altitude and level of malaria transmission $(p>0.05)$. In fact, the rate of access to LLIN was the lowest (32.3\%) in high malaria transmission areas whereas $42.7 \%$ and $44.1 \%$ of the households had sufficient LLIN in low and moderate transmission areas, respectively. Likewise, $43.6 \%(120 / 275) 39.4 \%(142 / 360)$ and $50.0 \%(37 / 74)$ of the households had sufficient access to LLIN in low, mid and high altitude areas, respectively.

\section{Use of LLIN among children}

Overall, 491 (69.3\%, 95\%CI: 65.8-72.7) of the caretakers reported that their children (aged 2-9 years old) slept under LLIN the previous night. Table 4 shows the association of caretakers' malaria related knowledge and other selected background factors with LLIN use by children. After it was adjusted for altitude, caretakers' knowledge of mosquito net was significantly associated with increased net use among children. Use of mosquito net was lower by $53.0 \%$ among children whose caretakers did not know that LLIN prevents malaria $(\mathrm{AOR}=0.47$, 95\%CI: $0.28-0.77, p=0.003)$. On the other hand, net use was significantly lower among children whose caretakers directly attributed causation of malaria to stagnant water $(\mathrm{AOR}=0.44,95 \% \mathrm{CI}:$ 0.22-0.89, $p=0.021)$. However, knowledge of mosquito bite and overall knowledge of malaria did not have associations with net use among children $(p>0.05)$. Of course, even though significant association did not exist, increased overall knowledge aligned with increased probability of net use among children (Fig. 3). Of the background factors included in the analysis, only family size was associated with net use among children in which increased family size was associated with reduced net use (Table 4).

\section{Relationship between caretakers' malaria related knowledge and care-seeking behavior for fever in children Prevalence of fever among children of 2-9 years old}

The study indicated that the two weeks' prevalence of fever was $17.2 \%(122 / 709)$ with very high heterogeneity by study sites $(p=0.001)$, altitude $(p=0.001)$ and malaria transmission levels $(p=0.007)$. Accordingly, the prevalence varied from $0.0 \%$ (in Dembi) to $34.1 \%$ (in Metehara). And, in terms of altitude, the highest prevalence of fever was recorded in low altitude areas $(22.9 \%, 63 / 275)$, followed by high altitude 
Table 4 Association of caretakers' malaria related knowledge and other selected background factors with LLIN use by children 2-9 years of age, Ethiopia

\begin{tabular}{|c|c|c|c|c|c|c|c|}
\hline \multirow[t]{2}{*}{ Variables } & \multicolumn{2}{|l|}{ Categories } & \multicolumn{2}{|c|}{ LLIN use previous night } & \multirow[b]{2}{*}{ Beta } & \multirow[b]{2}{*}{$P$-value } & \multirow[b]{2}{*}{ AOR $(95 \% \mathrm{Cl})$} \\
\hline & & & Yes & No & & & \\
\hline \multirow[t]{3}{*}{ Altitude ASL } & & Low $^{*}$ & $179(65.1)$ & $96(34.9)$ & & 0.180 & 1 \\
\hline & & Mid & $260(72.2)$ & $100(27.8)$ & -0.09 & 0.773 & $0.91(0.49-1.69)$ \\
\hline & & High & $52(70.3)$ & $22(29.7)$ & 0.26 & 0.398 & $1.29(0.71-2.35)$ \\
\hline \multirow[t]{2}{*}{ Residence } & & Rural & $338(65.9)$ & $175(34.1)$ & -0.53 & 0.014 & $0.59(0.39-0.89)$ \\
\hline & & Urban* & $153(78.1)$ & $43(21.9)$ & & & 1 \\
\hline \multirow[t]{6}{*}{ Knowledge of classical symptoms } & Fever & No & $272(70.6)$ & $113(29.4)$ & 0.05 & 0.798 & $1.06(0.70-1.59)$ \\
\hline & & Yes $^{*}$ & $219(67.6)$ & $105(32.4)$ & & & 1 \\
\hline & Chills & No & $131(62.4)$ & 79 (37.6) & -0.26 & 0.247 & $0.77(0.49-1.19)$ \\
\hline & & Yes $^{*}$ & $360(72.1)$ & $139(27.9)$ & & & 1 \\
\hline & Headache & No & $286(67.0)$ & $141(33.0)$ & -0.32 & 0.136 & $0.73(0.48-1.11)$ \\
\hline & & Yes $^{*}$ & $205(72.7)$ & $77(27.3)$ & & & 1 \\
\hline \multirow[t]{6}{*}{ Perceived causation of malaria } & Misquote bite & No & $157(66.0)$ & $81(34.0)$ & -0.13 & 0.602 & $0.88(0.55-1.42)$ \\
\hline & & Yes $^{*}$ & $334(70.9)$ & $137(29.1)$ & & & 1 \\
\hline & Stagnant water & No & $438(68.2)$ & $204(31.8)$ & -0.81 & 0.021 & $0.44(0.22-0.89)$ \\
\hline & & Yes $^{*}$ & $53(79.1)$ & $14(20.9)$ & & & 1 \\
\hline & Poor hygiene & No & $441(68.7)$ & $201(31.3)$ & -0.45 & 0.177 & $0.64(0.33-1.23)$ \\
\hline & & Yes $^{*}$ & $50(74.6)$ & $17(25.4)$ & & & 1 \\
\hline \multirow[t]{6}{*}{ Knowledge of prevention measures } & Sleeping under LLIN & No & $119(60.4)$ & 78 (39.6) & -0.76 & 0.003 & $0.47(0.28-0.77)$ \\
\hline & & Yes $^{*}$ & $372(72.7)$ & $140(27.3)$ & & & 1 \\
\hline & IRS & No & $457(69.3)$ & $202(30.7)$ & 0.30 & 0.388 & $1.35(0.68-2.69)$ \\
\hline & & Yes $^{*}$ & $34(68.0)$ & $16(32.0)$ & & & 1 \\
\hline & Environmental Management & No & $248(65.6)$ & $130(34.4)$ & -0.04 & 0.834 & $0.96(0.65-1.42)$ \\
\hline & & Yes $^{*}$ & $243(73.4)$ & $88(26.6)$ & & & 1 \\
\hline \multirow[t]{2}{*}{ Knowledge of vulnerable group } & $<5$ years old & No & $207(68.8)$ & $94(31.2)$ & -0.14 & 0.645 & $0.87(0.49-1.57)$ \\
\hline & & Yes $^{*}$ & $284(69.6)$ & $124(30.4)$ & & & 1 \\
\hline \multirow[t]{2}{*}{ Sex of child } & & Male & $257(69.1)$ & $115(30.9)$ & 0.01 & 0.953 & $1.01(0.72-1.42)$ \\
\hline & & Female* & $222(68.7)$ & $101(31.3)$ & & & 1 \\
\hline \multirow[t]{2}{*}{ Age of child } & & $<5$ & $213(70.5)$ & $89(29.5)$ & 0.05 & 0.781 & $1.05(0.74-1.48)$ \\
\hline & & $\geq 5^{*}$ & $266(67.7)$ & $127(32.3)$ & & & 1 \\
\hline \multirow[t]{3}{*}{ Malaria transmission levels } & & Low & $295(68.4)$ & $136(31.6)$ & -0.11 & 0.706 & $0.89(0.51-1.59)$ \\
\hline & & Moderate & $150(70.4)$ & $63(29.6)$ & -0.02 & 0.957 & $0.98(0.53-1.81)$ \\
\hline & & High* & $46(70.8)$ & $19(29.2)$ & & & 1 \\
\hline Overall knowledge & & & & & -0.01 & 0.589 & $0.99(0.98-1.01)$ \\
\hline Family size & & & & & -0.16 & 0.001 & $0.86(0.78-0.94)$ \\
\hline
\end{tabular}

*reference category

areas $(20.3 \%, 15 / 74)$, and the lowest prevalence of fever was recorded in mid altitude areas (12.2\%, 44/ 360 ). The prevalence of fever was also the highest in high malaria transmission areas (30.8\%), followed by low transmission areas (16.7\%). In moderate and low malaria transmission settings, the two weeks' prevalence of fever was $14.1 \%(30 / 213)$ and $16.7 \%$ (72/ 431), respectively.

\section{Care-seeking behavior for fever}

Of those children with fever $(n=122)$, only $50(41.0 \%)$ sought care from any source, with no significant differences by study sites, altitude and malaria transmission levels $(P>0.05)$. Of those who sought care, only 17 (34.0\%) sought the care promptly (within $24 \mathrm{~h}$ ) after onset of fever, with no substantial variability by study sites, altitude and transmission levels $(p>0.05)$. The 


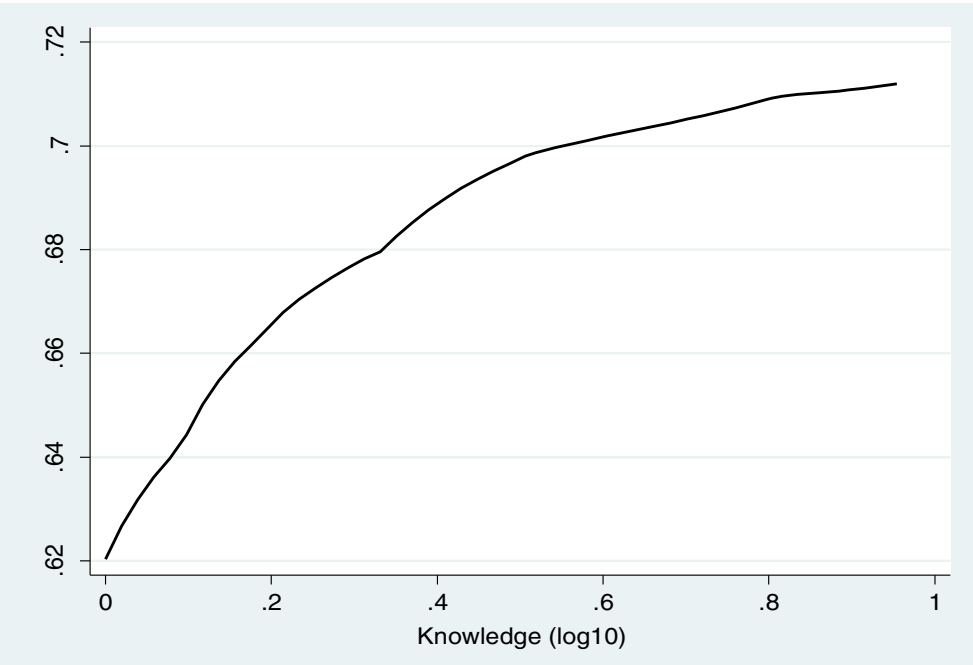

Fig. 3 Probability of net use by malaria related knowledge, Ethiopia

prevalence of prompt care-seeking was 33.3\% (10/30), $35.3 \%(6 / 17)$ and $1(33.3 \%)$ in low, mid and high altitude areas, respectively. Likewise, 37.0\% (10/27), 42.9\% (6/14), and $11.1 \%(1 / 11)$ sought prompt care in low, moderate and high transmission areas, respectively. Figure 4 shows the probability of seeking any care and prompt care. The probability of the two behaviors did not vary by age.

\section{Relationship between perceptions and care-seeking behaviors for fever among children}

Table 5 shows association of caretakers' malaria related perceptions/knowledge with care seeking behavior for febrile illness of their children. In this analysis, none of the malaria related knowledge items, including knowledge of classical signs and symptoms and overall knowledge, did show significant association with care-seeking behavior. However, care-seeking behavior was lower by $88.0 \%$ among caretakers whose children had never experienced malaria attack according to their perceptions as compared to those who reported no history of malaria attack (AOR $=0.12, \quad 95 \%$ CI: $0.04-0.36, p=0.001$ ). Similarly, careseeking behavior was higher among households with no or insufficient LLIN as compared to households with sufficient LLINs (AOR $=3.93$, 95\%CI: $1.39-11.12, p=0.010$ ).

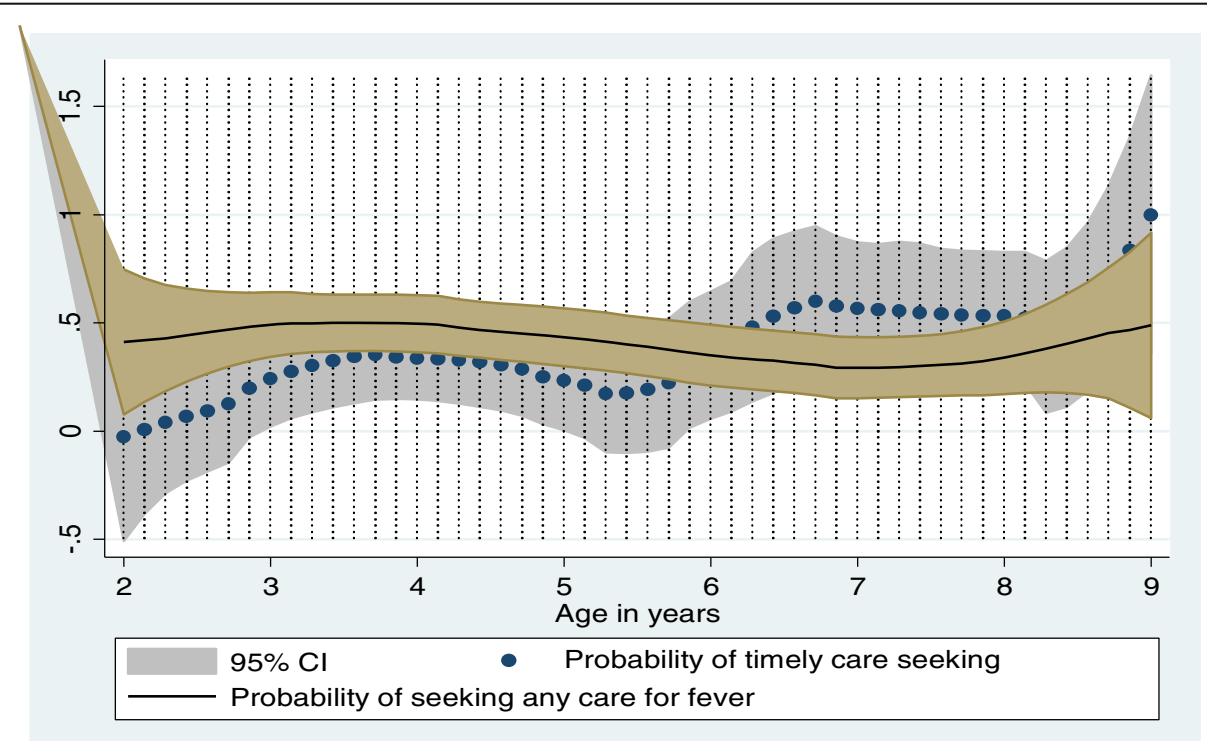

Fig. 4 Probability of care seeking for fever after onset of fever, Ethiopia 
Table 5 Association of caretakers' malaria related perceptions/knowledge with care seeking behavior for febrile illness of their children, Ethiopia

\begin{tabular}{|c|c|c|c|c|c|c|}
\hline \multirow[t]{2}{*}{ Variables } & \multirow[t]{2}{*}{ Categories } & \multicolumn{2}{|c|}{ Sought care } & \multirow[t]{2}{*}{ B } & \multirow[t]{2}{*}{$P$-value } & \multirow[t]{2}{*}{ AOR $(95 \% \mathrm{Cl})$} \\
\hline & & No & Yes & & & \\
\hline \multicolumn{7}{|l|}{ Perceived cause of malaria } \\
\hline \multirow[t]{2}{*}{ Mosquito bite } & No & $15(71.4)$ & $6(28.6)$ & -0.44 & 0.570 & $0.65(0.14-2.93)$ \\
\hline & Yes $^{*}$ & $57(56.4)$ & $44(43.6)$ & & & 1 \\
\hline \multirow[t]{2}{*}{ Stagnant water } & No & $71(59.7)$ & $48(40.3)$ & -2.26 & 0.177 & $0.10(0.00-2.77)$ \\
\hline & Yes* $^{*}$ & $1(33.3)$ & $2(66.7)$ & & & 1 \\
\hline \multicolumn{7}{|l|}{ Knowledge of prevention measures } \\
\hline \multirow[t]{2}{*}{ Sleeping under net } & No & $15(68.2)$ & $7(31.8)$ & 0.09 & 0.923 & $1.09(0.19-6.32)$ \\
\hline & Yes $^{*}$ & $57(57.0)$ & $43(43.0)$ & & & 1 \\
\hline \multirow[t]{2}{*}{ IRS } & No & $63(58.9)$ & $44(41.1)$ & 0.29 & 0.730 & $1.33(0.26-6.80)$ \\
\hline & Yes $^{*}$ & $9(60.0)$ & $6(40.0)$ & & & 1 \\
\hline Environmental management & No & $43(58.1)$ & $31(41.9)$ & -0.21 & 0.696 & $0.81(0.29-2.29)$ \\
\hline \multirow[t]{2}{*}{ Knowledge of classical symptoms of malaria } & No & $51(57.3)$ & $38(42.7)$ & 0.62 & 0.381 & $1.85(0.47-7.36)$ \\
\hline & Yes $^{*}$ & $21(63.6)$ & $12(36.4)$ & & & 1 \\
\hline \multirow[t]{2}{*}{ Knowledge of risky groups } & No & $62(59.0)$ & $43(41.0)$ & -0.03 & 0.972 & $0.97(0.15-6.40)$ \\
\hline & Yes* $^{*}$ & $10(58.8)$ & $7(41.2)$ & & & 1 \\
\hline \multirow[t]{2}{*}{ Overall knowledge } & & & & -0.01 & 0.983 & $0.99(0.62-1.60)$ \\
\hline & Yes $^{*}$ & $29(60.4)$ & 19 (39.6) & & & 1 \\
\hline \multirow[t]{2}{*}{ Own n LLIN } & Yes & $67(60.9)$ & $43(39.1)$ & -0.05 & 0.959 & $0.95(0.15-5.99)$ \\
\hline & $\mathrm{No}^{*}$ & $5(41.7)$ & $7(58.3)$ & & & 1 \\
\hline Previous net use & No & $19(51.4)$ & $18(48.6)$ & 0.53 & 0.389 & $1.70(0.51-5.73)$ \\
\hline \multirow[t]{3}{*}{ Households access to LLIN } & No & $40(52.6)$ & $36(47.4)$ & 1.37 & 0.010 & $3.93(1.39-11.12)$ \\
\hline & Yes* $^{*}$ & $32(69.6)$ & $14(30.4)$ & & & 1 \\
\hline & Yes* $^{*}$ & $53(62.4)$ & $32(37.6)$ & & & 1 \\
\hline \multirow[t]{2}{*}{ Ever got malaria (self-report) } & No & $43(79.6)$ & $11(20.4)$ & -2.14 & 0.000 & $0.12(0.04-0.36)$ \\
\hline & Yes $^{*}$ & $29(42.6)$ & $39(57.4)$ & & & 1 \\
\hline \multirow[t]{2}{*}{ Sex } & Male & $44(62.9)$ & $26(37.1)$ & -0.49 & 0.300 & $0.61(0.24-1.55)$ \\
\hline & Female* & $27(54.0)$ & $23(46.0)$ & & & 1 \\
\hline \multirow[t]{2}{*}{ Age in years } & $2-5$ & $28(53.8)$ & $24(46.2)$ & 0.66 & 0.166 & $1.94(0.76-4.95)$ \\
\hline & $\geq 5^{*}$ & $43(63.2)$ & $25(36.8)$ & & & 1 \\
\hline \multirow[t]{2}{*}{ Place of residence } & Rural & $50(66.7)$ & $25(33.3)$ & -1.39 & 0.008 & $0.25(0.09-0.69)$ \\
\hline & Urban* $^{*}$ & $22(46.8)$ & $25(53.2)$ & & & \\
\hline \multirow[t]{3}{*}{ Malaria transmission levels } & Low & $45(62.5)$ & $27(37.5)$ & -0.33 & $0^{0} .656$ & $0.72(0.17-3.08)$ \\
\hline & Moderate & $16(53.3)$ & $14(46.7)$ & -0.02 & 0.982 & $0.98(0.23-4.15)$ \\
\hline & $\mathrm{High}^{*}$ & 11 (55.0) & $9(45.0)$ & & 0.852 & 1 \\
\hline
\end{tabular}

*reference category

\section{Source of care for fever}

More than third $(38.0 \%, 19 / 50)$ of the persons who sought care consulted private clinics, and $32.0 \%(16 / 50)$ visited government health centers. Pharmacy and health post accounted for $24 \%(12 / 50)$ and $6 \%(3 / 50)$, respectively. Figure 5 shows the probability of treatment source preference for febrile illness of children by malaria endemicity/transmission levels $(p<0.05)$. Accordingly, the probability of using private clinic was increased with increased malaria endemicity levels whereas the probability of visiting government health facilities and pharmacies decreased as the malaria endemicity levels increased. In low transmission areas, $40.7 \%(7 / 27)$ of the caretakers consulted pharmacies and $(33.3 \%, 9 / 27)$ visited government health facilities. Private clinics were consulted by $25.9 \% \quad(7 / 27)$. In contrast, in high 


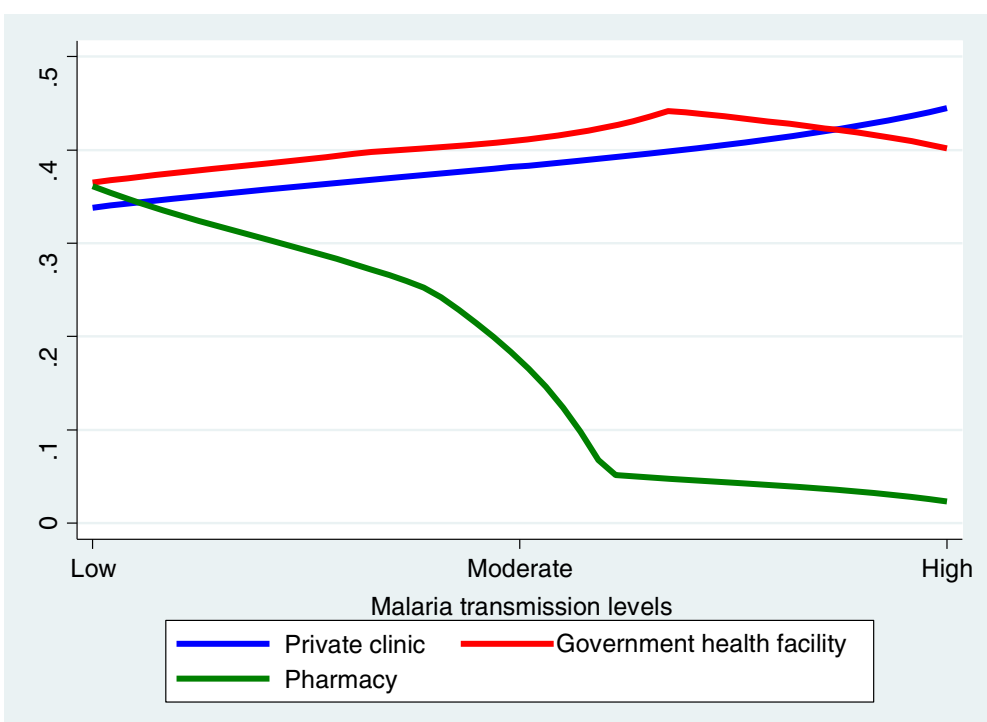

Fig. 5 The probability of visiting some source of care for fever by malaria endemicity level

transmission areas, $66.7 \%(3 / 9)$ of the febrile children visited private clinics and the remaining visited government health facilities. In areas where malaria transmission was moderate, 50 (7/14), $42.9 \%(6 / 14)$ and $7.1 \%(1 / 14)$ of the febrile children visited government facilities, private clinics and pharmacies, respectively. Figure 6 shows the probability of treatment source preference by overall malaria related knowledge. Accordingly, higher knowledge score was positively correlated with preference of pharmacy as treatment option $(r=0.759, \quad p=0.044)$. However, preference of private clinics and government health facilities did not have significant association with overall malaria knowledge of caretakers.
Blood test among those who sought care for fever

Of those who reported visiting health facilities for fever $(n=50), 29(58.0 \%)$ said that their children were tested for blood examination. The proportion of subjects who received blood test was significantly higher in government health facilities $(84.2 \%, 16 / 19)$ and in private clinics $(68.4 \%, 13 / 19) \quad(p=0.001)$. And those who consulted pharmacy did not receive any test.

\section{Discussion}

This study assessed malaria related knowledge and perceptions among caretakers of children aged 2-9 years and examined the association between knowledge and use of LLIN and care-seeking for their children, in

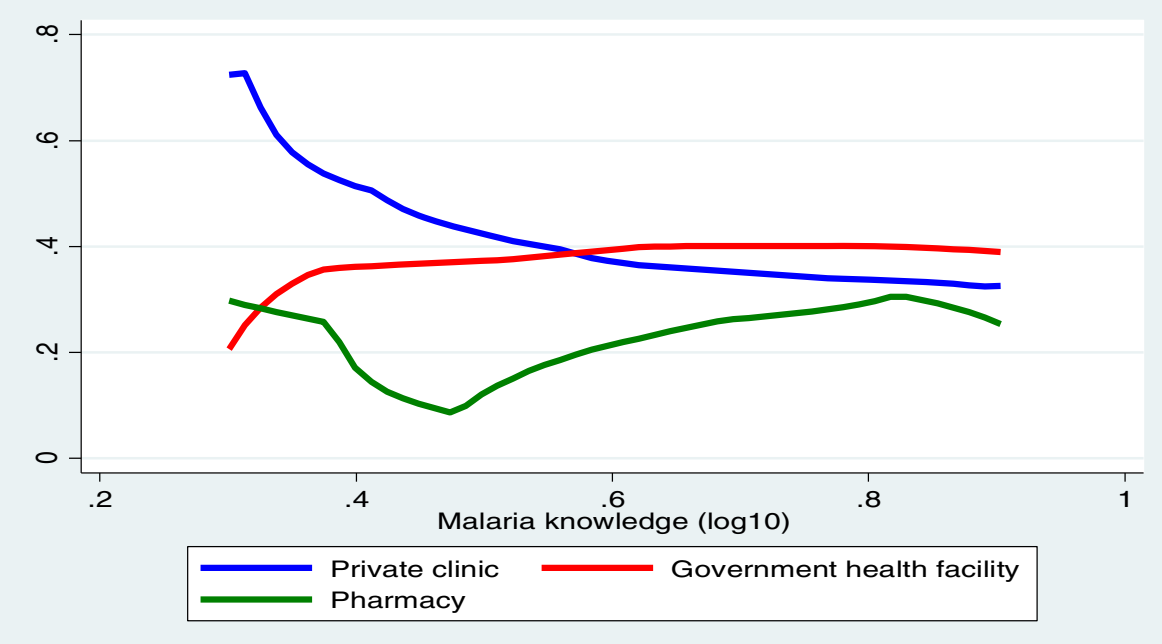

Fig. 6 Probability of treatment source preference for fever by overall knowledge, Ethiopia 
different malaria transmission settings of Ethiopia. Local understanding of malaria and its preventive strategies are at heart of successful malaria prevention and control program [20, 34-36]. In this study, familiarity with the disease 'malaria' was universal across different ecological settings-lowlanders to highlanders in Ethiopia. Some earlier studies, in Ethiopia and elsewhere [11, 37, 38], documented that a significant proportion of community members had never heard of malaria [39]. In this study, most caretakers recognized malaria by chills. However, fever was less recognized by caretakers of children and it was low as compared to some previous studies in Ethiopia [38, 40-42] and elsewhere [39, 43]. Of course, differences in the populations studied and geographic and contextual variations might have accounted for the differences in local perceptions and recognitions of malaria. Currently, malaria has significantly declined in Ethiopia [7, 12, 13], and this could affect peoples' ability to recognize malaria which was also reflected in this study as overall knowledge of malaria was found to be low in low malaria transmission settings. Thus, it is crucial to make the public stay well informed about the classical signs and symptoms of malaria.

It is crucial for community members to make a correct link between malaria and mosquito bite to apply recommended preventive measures such as utilization of LLINs. In this study, the proportion of caretakers who knew correct route of malaria transmission was low. In some study localities, especially in low malaria transmission areas and high altitude settings, the vast majority of the caretakers did not have awareness of the routine of malaria transmission. Unexpectably, various misconceptions such as directly associating malaria to poor sanitations and hygiene, weather conditions, dirty water, hunger and eating different diets were widely prevalent in the study communities. Literatures show a wide range of findings regarding community knowledge on the link between malaria and mosquito bite. Some studies documented better knowledge status on the link between mosquito bite and malaria [38, 40, 42, 44] while some other studies reported quite comparable results with the present findings [37, 41, 43, 45]. Such local beliefs and perceptions could continue to influence correct impressions of malaria and use of preventive measures [20,36]. This suggests that awareness building activities need to be location-specific and tailored to local level knowledge gaps and barriers.

On the other hand, knowledge of scientifically proven malaria preventive measures is a prerequisite to motivate community members to adopt and adhere to malaria preventive practices particularly in low transmission settings. In this study, three quarters of caretakers knew that sleeping under insecticide treated mosquito net prevents malaria, which is comparable with some previous findings [11, 37, 40, 46]. However, in some localities, Dembi, Kersa and Shebe Sombo, only few people knew that insecticide treated mosquito nets can prevent malaria. On the other hand, knowledge regarding the role of IRS was exceptionally low among caretakers which might suggest that households' experience with IRS might be low. Consistent with many previous studies [38, 40, 45-47], a significant number of caretakers emphasized the role of environmental management and sanitation in malaria prevention and control. In fact, environmental sanitation is very important to control mosquito breeding sites, and thus, need to be promoted in all malaria transmission settings in such a way that people could be able to develop proper understanding on how poorly managed environment encourages malaria transmission.

In this study, caretakers' knowledge of most vulnerable groups to malaria infections was not adequate. In fact, children under the age of five were frequently mentioned as vulnerable groups whereas pregnant women were infrequently mentioned as vulnerable groups. In many high malaria endemic settings, it is true that pregnant women and children are more vulnerable to malaria [48]. However, it must be noted that in the context of reduced transmission of malaria, most people often lack protective immunity, and thus, all people are at higher risk of malaria. Therefore, malaria program needs to reiterate the historical malaria messaging approaches that focus on children and pregnant women as primary target groups for malaria communications. Overall knowledge about malaria was inadequate in the settings of this study, especially in areas where the level of malaria transmission was low, and it was much lower compared to some earlier studies $[37,40]$. In areas where malaria burden is significantly reduced, people may become increasingly reluctant and less concerned about malaria which in turn can lead to dropping of malaria related knowledge and perceptions of personal risks [20].

This study revealed that ownership of LLIN was generally high (92.8\%) in the study population and it was close to the national target (i.e. 100\% coverage) [12]. The coverage was somewhat higher as compared to previous reports [11, 32, 33, 49-52]. Despite quite high ownership of nets, the proportion of households who had sufficient access to nets (i.e. 1 LLIN for every two people) was very low (42.2\%) and far behind the national and global target for malaria elimination agenda $[1,12]$. Moreover, access gap significantly varied by localities and was very high in some study areas. Nevertheless, rate of access did not significantly vary by altitude and levels of malaria transmission which might suggest lack of targeted and need based distribution of mosquito nets in Ethiopia. Thus, even though a remarkable success has been achieved in availing at least one net for each household, this study 
documented a huge access gap which needs further efforts to ensure and maintain universal coverage of nets in all malaria endemic areas.

Use of LLINs is one of the most recommended malaria vector control strategies, especially in tropical areas [53-56]. Consequently, the rate of LLIN use was fairly high (69.3\%) among the target groups assessed in this study and it was higher compared to national average of LLIN use among children under the age of five, pre-school children and the general population [11]. Additionally, the present findings show higher LLIN user coverage compared to some earlier studies $[9,30,32,33,49,51,52,57-63]$. Some studies showed that net use can be affected by seasonality and perceived presence of mosquito $[11,50,58]$, and since this study was conducted in a malaria transmission season, a higher user coverage of LLIN could be expected. In fact, caretakers were interviewed in health facilities which might have caused social desirability bias whereby caretakers over reported use of LLIN. In this study, only knowledge about role of mosquito net significantly contributed to increased LLIN use among children, i.e. caretakers who knew that LLINs prevents malaria were better practicing net use. On the other hand, net use was significantly affected by the belief that assumed malaria is the direct result of stagnant water-people who directly attributed malaria to stagnant water were less likely to use nets. Other dimensions of malaria related knowledge such as knowledge on route of transmission, vulnerable groups and overall knowledge were not significant mediators or motivators for net use. In behavioral changes steps, changes in behavior are mediated by appropriate level of knowledge [64], and as a result, one of the major tasks in community education program is improving knowledge about health issues. In fact, knowledge alone may be insufficient to change behavior; however, it can be highly motivating and is an essential prerequisite to perform the desired behavior [64]. Thus, in order to promote LLIN use, malaria education program can be focused on enhancing the role of insecticide mosquito while addressing supply side factors that may affect use of nets.

This study indicated that caretakers' care-seeking behavior for febrile illness of their children was very poor and low as compared to earlier studies [11, 40, 65-70]. Moreover, caretakers' habit of prompt care seeking was quite low indicating that early and effective diagnosis and management remain a critical challenge in malaria control programs in such endemic settings. Moreover, private health facilities remain a significant source of care for fever/malaria. Nevertheless, private health facilities, especially in peripheral areas, have poor linkage with public health facilities and have limited diagnostic facilities which further increase malaria surveillance and monitoring difficulties. In principle, early recognition of malaria and knowledge of the classical signs and symptom of malaria is crucial in motivating people to seek care from appropriate health source of care [1, 22, 64]. In this study, however, none of the caretakers' malaria related knowledge, including overall knowledge, was causally associated with care-seeking behavior in any direction. This implies that any level of knowledge on malaria, its causality and prevention strategies are not a guarantee for prompt and appropriate care-seeking practices, instead outside head determinants of behavior such as resource, social factors, and health services dimensions might have played significant role. Of course, level of malaria knowledge had an impact on treatment source preference where people with better knowledge tended to use pharmacies or drug vendors as source of treatment. However, level of knowledge did not play a significant role in influencing the decision to choose between private and public health facilities. Past perceived experience of malaria attack was found to be an important motivator for care-seeking for recent experience of fever. This suggests that past behavioral exercises and experiences are important mediators since people might have learned the pros and cons of care-seeking and have also exercised the behavior. Another interesting finding in this study was that adequate access to LLIN negatively affected care-seeking behavior for fever. Perhaps, access to LLIN negatively influenced households' perceptions of vulnerability to malaria infections thereby affecting care-seeking behavior for fever.

This study might have some limitations. Overall knowledge was computed by summing up most important items to produce a composite score. Composite score is easier to interpret and facilitate understanding. However, it assumes that all items have equal contributions which may not be the case. Consequently, it does not allow for differentiation of high and low scores on a specific knowledge item. Nevertheless, item-based analysis was performed for most important items which could help to complement the limitation of using composite score. In addition, the findings of this study might have been affected by response bias due to the fact that caretakers were interviewed in health facilities. This is because facility based studies produce more positive responses by caretakers. Moreover, the data were collected mainly from sentinel surveillance sites in Ethiopia which may not represent all malaria transmission settings in the county.

\section{Conclusions}

This study revealed that local understanding of malaria was unsatisfactory and very limited in some localities with arrays of misconceptions on causalities and prevention strategies. On the other hand, access to and use of 
LLIN were low and far behind set targets in the studied communities. Additionally, caretakers' habit of prompt care-seeking for febrile illness of their children was not optimal. Furthermore, significant proportions of caretakers, especially in areas with high transmission, preferred private health facilities for treatment of malaria where the practice of test and treat is basically low. This further increases surveillance and monitoring difficulties which is a key in elimination program. Ideally, higher knowledge about a disease and its prevention practices (i.e. malaria and its prevention strategies) produces positive protective behavior. However, the evidence in this study depicted that only knowledge of the benefits of LLIN positively mediated use of LLIN. In fact, some beliefs such as attributing malaria to stagnant water discouraged use of LLIN. Moreover, there was no significant link between caretakers' knowledge of malaria and care-seeking behavior, but level of knowledge may affect treatment source preference for malaria. Lack of proper connection between malaria related knowledge and desired malaria preventive practices suggests that knowledge was not sufficient to drive use of LLIN and careseeking. This may suggest that caretakers' knowledge may not be influential in terms of use of LLIN and care seeking at household level. Nevertheless, it is not possible to underestimate the role of knowledge in mediating malaria preventive behavior since, without adequate knowledge, people may be unaware of the health problems and the need to take preventive actions. Thus, despite lack of strong linkage between knowledge of malaria and use of LLIN and care-seeking, it important to build and maintain broader understandings of malaria and its preventive strategies (especially environmental management, role of mosquito and ways to control it) and the importance of prompt care-seeking. Thus, well-planned and locally sensitive ongoing public educational interventions are essential to educate and help communities to improve and sustain malaria related knowledge and desired protective behavior while addressing external factors such as access to LLIN.

\section{Abbreviations \\ ASL: Above Sea Level; EIA: Enzyme Immuno Assay; HDA: Health Development Army; HEP: Health Extension Program; HEWs: Health Extension Workers; IRS: Indoor Residual Spraying; LLIN: Long Lasting Insecticide Treated Net; PHCUs: Primary Health Care Units; RDT: Rapid Diagnostic Test; SM: Serological Marker; TDR: Tropical Disease Research; WHO: World Health Organization}

\section{Acknowledgements}

We express our heartfelt thanks to World Health Organization Special Programme for Research and Training in Tropical Diseases for financing the study. We also express our appreciation to the study participants for their cooperation in providing the necessary information. We acknowledge Jimma University, local administrators, and the community for their strong support during the survey. The authors also express deepest appreciation to field data collectors namely Damtew Feyisa, Silesh Kenate, and Daniel Emana.

\section{Funding}

This study was supported by World Health Organization Special Programme for Research and Training in Tropical Diseases (TDR) (Protocol ID: B40082). $\mathrm{WHO}$ was not involved in design, collection analysis and interpretation of data. However, WHO has reviewed and approved the study.

\section{Availability of data and materials}

The datasets during and/or analyzed during the current study are available from the corresponding author on reasonable request.

\section{Authors' contributions}

ZB conceived the study; was involved in the design and conduct of the study. DY and $Y Y$ involved in the design and conduct of the study. ZB drafted the manuscript and DY and $Y Y$ critically reviewed the manuscript for intellectual content. ZB revised the manuscript and all authors read and approved the final version of the manuscript.

\section{Ethics approval and consent to participate}

The study was reviewed and approved by Institutional Review Board of Jimma University (Ref.No. RPGC/112/2015 and World Health organization Ethics review committee (Protocol ID: B40082, approval date: 15/06/2015). In addition, the study was reviewed and approved by Oromia Regional Health Bureau (Ref.No.BEFO/AHITQFTF050/83). Caretakers were provided detail information about the study through a consent process and informed written consent was obtained from all participated caretakers.

\section{Consent for publication}

Not applicable.

\section{Competing interests}

The authors declared that they have no competing interests.

\section{Publisher's Note}

Springer Nature remains neutral with regard to jurisdictional claims in published maps and institutional affiliations.

\section{Author details}

${ }^{1}$ Department of Health, Behavior and Society, Faculty of Public Health, Jimma University, Jimma, Ethiopia. ${ }^{2}$ Abt Associates, Africa Indoor Residual Spraying, Accra, Ghana. ${ }^{3}$ Department of Medical Laboratory Sciences and Pathology, Faculty of Health Sciences, Jimma University, Jimma, Ethiopia. ${ }^{4}$ Tropical and Infectious Diseases Research Center, Jimma University, Jimma, Ethiopia.

Received: 17 October 2016 Accepted: 12 September 2017

Published online: 18 September 2017

\section{References}

1. World Health Organization. Global malaria technical strategy for malaria 2016-2030. 2015 [cited 2016 Aug 22]. Available from: http://www.who.int/ malaria/areas/global_technical_strategy/en/.

2. CDC - Malaria - About Malaria - Disease. [cited 2017 Feb 16]. Available from: https://www.cdc.gov/malaria/about/disease.html.

3. World Health Organization. Manual of epidemiology and epidemiological services in malaria programmes. World Health Organization; 1968 [cited 2016 Dec 12]. Available from: http://apps.who.int/iris/bitstream/10665/ 40401/1/924154015X.pdf.

4. World Health Organization. World health Organization. Malaria case management: operations manual. World Health Organization; 2009 [cited 2016 Aug 22]. Available from: http://www.who.int/malaria/publications/atoz/ 9789241598088/en/.

5. World Health Organization. World Malaria Report 2016. Geneva: Word Health Organization; 2016 [cited 2017 Oct 1]. Available from: http://www. who.int/malaria/publications/world-malaria-report-2015/report/en/.

6. World Health Organization. World Malaria Report [Internet]. Geneva: Word Health Organization; 2015 [cited 2016 Dec 12]. Available from: http://www. who.int/malaria/publications/world-malaria-report-2015/report/en/[cited.

7. Ministry of Health [Ethiopia]. Health sector development program IV: final report. Addis Ababa: Ministry of Health; 2010 [cited 2016 Aug 22]. Available from: http://phe-ethiopia.org/admin/uploads/attachment-721HSDP\%20IV\%20Final\%20Draft\%20110ctoberr\%202010.pdf. 
8. Ethiopian Health and Nutrition Research Institute. Ethiopia National Malaria Indicator Survey. Addis Ababa: Ethiopian Health and Nutrition Research Institute; 2007 [cited 2016 Aug 22]. Available from: https://www.cartercenter. org/resources/pdfs/news/health_publications/malaria/ethiopia_2007_mis_ report.pdf.

9. Ethiopian Health and Nutrition Research Institute; Ethiopia National Malaria Indicator Survey. Addis Ababa: Ethiopian Health and Nutrition Research Institute; 2011 [cited 2016 Dec 8]. Available from: https://www.unicef.org/ ethiopia/ET_MIS_2011_Report.pdf.

10. Admasu K. The Implementation of the Health Development Army: Challenges, Perspectives and Lessons Learned with a Focus on Tigray's Experience. Q Health Bull. 2013;5(1):3-7.

11. Ethiopian Public Health Institute. Ethiopia National Malaria Indicator Survey 2015. Addis Ababa; 2016 [cited 2017 Jan 1]. Available from: http://www. ephi.gov.et/images/pictures/download2009/MIS-2015-Final-ReportDecember-_2016.pdf.

12. Ministry of Health [Ethiopia]. National malaria strategic plan 2014-2020. Addis Ababa: Ministry of Health; 2014.

13. Aregawi M, Lynch M, Bekele W, Kebede H, Jima D, Taffese HS, et al. Time series analysis of trends in malaria cases and deaths at hospitals and the effect of antimalarial interventions, 2001-2011, Ethiopia. PLoS One. 2014; 9(11):e106359.

14. Ministry of Health [Ethiopia]. Annual health performance report. Addis Ababa: Ministry of Health; 2015. p. 26-7.

15. Ministry of Health [Ethiopia]. Health and Health related indicators. Addis Ababa: 2014 2015. p. 17-21

16. Ministry of Health [Ethiopia]. Annual health performance report. Addis Ababa: Ministry of Health; 2014

17. WHO/Roll Back Malaria Partnership. Action and Investment to Defeat Malaria 2016-2030. World Health Organization; 2015 [cited 2016 Mar 28]. Available from: http://www.rollbackmalaria.org/files/files/aim/RBM_AIM_Report_A4_ EN-Sept2015.pdf.

18. World Health Organization. Global Partnership for malaria free world. World Health Organization; 2008 [cited 2016 Sep 23]. Available from: http://www. rollbackmalaria.org/microsites/gmap/rbmgmap.html.

19. Ministry of Health [Ethiopia]. Health Sector Transformation Plan. Addis Ababa: Ministry of Health; 2015.

20. Whittaker $M$, Smith $C$. Reimagining malaria: five reasons to strengthen community engagement in the lead up to malaria elimination. Malar J. 2015;14:410.

21. Ministry of Health [Ethiopia]. National strategic plan for malaria prevention control and elimination in Ethiopia 2011-2015. Addis Ababa: Ministry of Health; 2011.

22. WHO. T3: Test. Treat. Track initiative. [cited 2017 Jan 15]. Available from: http://www.who.int/malaria/areas/test_treat_track/en/

23. WHO. Guidelines for the treatment of malaria. Third edition. [cited $2017 \mathrm{Jan}$ 15]. Available from: http://www.who.int/malaria/publications/atoz/ 9789241549127/en/

24. WHO. WHO informal consultation on fever management in peripheral health care settings: A global review of evidence and practice. [cited 2017 Jan 15]. Available from: http://www.who.int/malaria/publications/atoz/ 9789241506489/en/

25. Ministry of Health [Ethiopia]. Health extension implementation guide. Addis Ababa: Ministry of Health; 2007.

26. Birhanu Z, Yihdego YY, Emana D, Feyissa D, Kenate S, Kebede E, et al. Relationship between exposure to malaria and haemoglobin level of children 2-9 years old in low malaria transmission settings. Acta Trop. 2017; 173:1-10.

27. Yukich JO, Butts J, Miles M, Berhane $Y$, Nahusenay $H$, Malone $J$, et al. A description of malaria sentinel surveillance: a case study in Oromia Regional State, Ethiopia. Malar J. 2014;13(1):1-13.

28. United States Agency for International Development/President Malaria Initiative. Malaria Epidemic Detection Initiative in Oromia, Ethiopia. Newsletter. 2011;1(6)

29. Ethiopian Health and Nutrition Research Institute (EHNRI). Manual for the Laboratory Diagnosis of Malaria. Ministry of Health; Addis Ababa; 2012 [cited 2017 Jan 15]. Available from: https://www.scribd.com/document/ 240276896/Manual-for-the-Laboratory-Diagnosis-of-Malaria\#.

30. Central Statistical Agency of Ethiopia. Ethiopian demographic and health survey [Internet]. Addis Ababa: Central Statistical Agency of Ethiopia; 2011 [cited 2016 Dec 8]. Available from: https://www.unicef.org/ethiopia/ET_2011_EDHS.pdf
31. Malaria ElA Ab Assay | Clinical Diagnostics | Bio-Rad. [cited 2016 Nov 8]. Available from: http://www.bio-rad.com/en-ca/product/malaria-eia-ab-assay.

32. Terlouw DJ, Morgah K, Wolkon A, Dare A, Dorkenoo A, Eliades MJ, et al. Impact of mass distribution of free long-lasting insecticidal nets on childhood malaria morbidity: The Togo National Integrated Child Health Campaign. Malar J. 2010:9:199.

33. Kulkarni MA, Eng JV, Desrochers RE, Cotte AH, Goodson JL, Johnston A, et al. Contribution of Integrated Campaign Distribution of Long-Lasting Insecticidal Nets to Coverage of Target Groups and Total Populations in Malaria-Endemic Areas in Madagascar. Am J Trop Med Hyg. 2010;82(3):420-5.

34. Beier JC, Keating J, Githure Jl, Macdonald MB, Impoinvil DE, Novak RJ. Integrated vector management for malaria control. Malar J. 2008:7(1):1-10.

35. Bamidele JO, Ntaji MI, Oladele EA, Bamimore OK. Community Participation in Malaria Control in Olorunda Local Government Area, Osun State, Southwestern Nigeria. Afr J Infect Dis. 2012;6(2):24-8.

36. Atkinson J-AM, Fitzgerald L, Toaliu H, Taleo G, Tynan A, Whittaker M, et al. Community participation for malaria elimination in Tafea Province, Vanuatu: Part I. Maintaining motivation for prevention practices in the context of disappearing disease. Malar J. 2010;9:93.

37. Gobena T, Berhane Y, Worku A. Women's knowledge and perceptions of malaria and use of malaria vector control interventions in Kersa, eastern Ethiopia. Glob Health Action. 2013 [cited 2016 Sep 12];6(0). Available from: http://www.globalhealthaction.net/index.php/gha/article/ view/20461.

38. Gutasa A, Assefa D, Kumela K. Assessment of Knowledge and Practice of the Community towards Malaria and its Treatment in Jiren Kebele, Jimma Town Oromia, Ethiopia. Adv Pharmacol Pharm. 2015;3(2):23-9.

39. Kimbi HK, Nkesa SB, Ndamukong-Nyanga JL, Sumbele IU, Atashili J, Atanga $\mathrm{MB}$. Knowledge and perceptions towards malaria prevention among vulnerable groups in the Buea Health District, Cameroon. BMC Public Health. 2014;14(1):1-9.

40. Birhanu Z, Abebe L, Sudhakar M, Dissanayake G, Yihdego YY, Alemayehu G, et al. Malaria Related Perceptions, Care Seeking after Onset of Fever and Anti-Malarial Drug Use in Malaria Endemic Settings of Southwest Ethiopia. PLoS One. 2016:11(8):e0160234

41. Habtamu BB, Nigus TF, Asrat MH. Knowledge, Attitude and Practice on Malaria and Associated Factors among Residents in Pawe District, North West Ethiopia: A Cross-Sectional Study. Sci J Pub Health. 2015;3(3):303-9.

42. Abate A, Degarege A, Erko B. Community knowledge, attitude and practice about malaria in a low endemic setting of Shewa Robit Town, northeastern Ethiopia. BMC Public Health. 2013;13:312.

43. Suuk Laar A, Kankponang A, Ayizem Ph. Community perception of malaria and its influence on health seeking behaviour in rural Ghana: a descriptive study. Mal Worl J. 2013:4(1).

44. Mayala BK, Fahey CA, Wei D, Zinga MM, Bwana VM, Mlacha T, et al. Knowledge, perception and practices about malaria, climate change, livelihoods and food security among rural communities of central Tanzania. Infect Dis Poverty. 2015 [cited 2016 Sep 12];4. Available from: http://www. ncbi.nlm.nih.gov/pmc/articles/PMC4408568/.

45. Mazigo HD, Obasy E, Mauka W, Manyiri P, Zinga M, Kweka EJ, et al. Knowledge, Attitudes, and Practices about Malaria and Its Control in Rural Northwest Tanzania. Malar Res Treat. 2010;2010:e794261.

46. Adebayo AM, Akinyemi OO, Cadmus EO. Knowledge of malaria prevention among pregnant women and female caregivers of under-five children in rural southwest Nigeria. PeerJ. 2015;3:e792.

47. Serengbe GB, Moyen J-M, Fioboy R, Beyam EN, Kango C, Bangue C, et al. Knowledge and perceptions about malaria in communities in four districts of the Central African Republic. BMC Res Notes. 2015;8:162.

48. World Health Organization. Roll Back Malaria Partnership. Evidence for advocacy: Malaria 2015 update, key statistics on the fight against malaria. Geneva: 2015 [cited 2016 Aug 23]. Available from: http://www. makingmalariahistory.org/wp-content/uploads/2015/06/Malaria_Evidencefor-Advocacy_April_2015.pdf.

49. Hightower A, Kiptui R, Manya A, Wolkon A, Vanden Eng JL, Hamel M, et al. Bed net ownership in Kenya: the impact of 3.4 million free bed nets. Malar J. 2010;9:183.

50. Birhanu Z, Abebe L, Sudhakar M, Dissanayake G, Yihdego Y, Alemayehu G, et al. Access to and use gaps of insecticide-treated nets among communities in Jimma Zone, southwestern Ethiopia: baseline results from malaria education interventions. BMC Public Health. 2015;15(1):1. 
51. Haileselassie B, Haileselassie B, Ali A. Assessment of Insecticide Treated Nets Coverage for Malaria Control in Kafta-Humera District, Tigray: Possession versus Use by High-risk Groups. Ethiop J Health Dev. 2008;22(3):259-67.

52. Deribew et al. Research Effect of training on the use of long-lasting insecticide-treated bed nets on the burden of malaria among vulnerable groups, south-west Ethiopia: baseline results of a a luster randomized trial. Malar J. 2010 [cited 2016 Nov 8];9(121). Available from: https://doi.org/10. 1186/1475-2875-11-8.

53. World Health Organization. Insecticide-Treated Mosquito Nets: A WHO Position Statement. World Health Organization; 2007.

54. Roll Back Malaria Partnership. Changes to guidance for vector control indicators: Meeting report of the 17th MERG meeting, 15-17.6. New York; 2011 [cited 2015 Mar 21]. Available from: https:/drive.google.com/file/d/OB8nOa3auYfABODZmZm Y1ZGEtNmVmNCOONmNiLWEZMDQtM2RiYTK2N2Q5NTEy/Niew.

55. Roll Back Malaria/WHO. Guidelines for core population-based indicators: RBM Technical Working Paper [Internet]. Roll Back Malaria. 2009 [cited 2015 Oct 3]. Available from: https://reliefweb.int/sites/reliefweb.int/files/resources/ AC719D00E5DE6F5D492575B3001BE5A3-RMB-guideline-20009.pdf.

56. Malaria Policy Advisory Committee to the WHO. Conclusions and recommendations of March 2013 meeting. Malar J. 2013;12:213.

57. Atieli HE, Zhou G, Afrane Y, Lee M-C, Mwanzo I, Githeko AK, et al. Insecticide-treated net (ITN) ownership, usage, and malaria transmission in the highlands of western Kenya. Parasit Vectors. 2011:4:113.

58. Baume CA, Reithinger $R$, Woldehanna S. Factors associated with use and non-use of mosquito nets owned in Oromia and Amhara Regional States, Ethiopia. Malar J. 2009:8:264.

59. Karunamoorthi K, Bekele M. Changes in Malaria Indices in an Ethiopian Health Centre: A Five Year Retrospective Analysis. Health Scope. 2012;1(3): $118-26$.

60. Zhou G, Li JS, Ototo EN, Atieli HE, Githeko AK, Yan G. Evaluation of universal coverage of insecticide-treated nets in western Kenya: field surveys. Malar J. 2014;13:351.

61. Githinji S, Herbst S, Kistemann T, Noor AM. Mosquito nets in a rural area of Western Kenya: ownership, use and quality. Malar J. 2010;9:250.

62. Garley AE, Ivanovich E, Eckert E, Negroustoueva S, Ye Y. Gender differences in the use of insecticide-treated nets after a universal free distribution campaign in Kano State, Nigeria: post-campaign survey results. Malar J. 2013;12:119.

63. Kilian A, Koenker H, Baba E, Onyefunafoa EO, Selby RA, Lokko K, et al. Universal coverage with insecticide-treated nets - applying the revised indicators for ownership and use to the Nigeria 2010 malaria indicator survey data. Malar J. 2013;12:314.

64. Simons-Morton BG, Greene WH, Gottlieb NH. Introduction to Health Education and Health Promotion. 2 Sub ed. Prospect Heights: Waveland Pr Inc; 1995. p. 510

65. Budhathoki CB, BC RK. Perceptions of Malaria and pattern of treatment seeking behaviour among Tharu and Pahari communities of Jhalari. J Nepal Health Res Counc. 2008;6(2):84-92.

66. Deressa W. Treatment-seeking behaviour for febrile illness in an area of seasonal malaria transmission in rural Ethiopia. Malar J. 2007:6:49.

67. Malik EM, Hanafi K, Ali SH, Ahmed ES, Mohamed KA. Treatment-seeking behaviour for malaria in children under five years of age: implication for home management in rural areas with high seasonal transmission in Sudan. Malar J. 2006;5:60

68. Njau JD, Goodman C, Kachur SP, Palmer N, Khatib RA, Abdulla S, et al. Fever treatment and household wealth: the challenge posed for rolling out combination therapy for malaria. Tropical Med Int Health. 2006;11(3):299-313.

69. Smith LA, Bruce J, Gueye L, Helou A, Diallo R, Gueye B, et al. From fever to antimalarial: the treatment-seeking process in rural Senegal. Malar J. 2010;9:333.

70. Alegana VA, Wright JA, Pentrina U, Noor AM, Snow RW, Atkinson PM. Spatial modeling of healthcare utilisation for treatment of fever in Namibia. Int J Health Geogr. 2012;11:6.

\section{Submit your next manuscript to BioMed Central and we will help you at every step:}

- We accept pre-submission inquiries

- Our selector tool helps you to find the most relevant journal

- We provide round the clock customer support

- Convenient online submission

- Thorough peer review

- Inclusion in PubMed and all major indexing services

- Maximum visibility for your research

Submit your manuscript at www.biomedcentral.com/submit
Biomed Central 